\title{
Must we cross the wall to get to the other side?
}

Adam E. Saltman, MD, PhD

See related article on page 355
From the University of Massachusetts Memorial Medical Center, Division of Cardiothoracic Surgery, Worcester, Mass.

Dr. Adam Saltman has consulted for Guidant, the manufacturers of microwave Flex -10 device.

Received for publication March 31, 2006; accepted for publication April 11, 2006.

Address for reprints: Adam E. Saltman, MD, $\mathrm{PhD}$, Director, CT Surgery Research, CoDirector, AF Center, Maimonides Medical Center, 4802 Tenth Avenue, Brooklyn, NY 11219 (E-mail: asaltman @ maimonidesmed. org).

J Thorac Cardiovasc Surg 2006;132:224-5

$0022-5223 / \$ 32.00$

Copyright $(\odot) 2006$ by The American Association for Thoracic Surgery

doi:10.1016/j.jtcvs.2006.04.003
I $\mathrm{n}$ this issue of the Journal, Melby and colleagues ${ }^{1}$ present a preclinical study of microwave radiation used to ablate the atrium of the beating heart. It is the first article to address the important issue of ablation effectiveness when energies are applied to the epicardium of the beating, working heart with a device that lends itself to a minimal-access approach. It is an important initial contribution to our nascent knowledge base, and it is a well-performed study.

There are 2 very important overarching questions raised by this type of research. The first really concerns the future of atrial fibrillation surgery: Can ablative energy sources create truly transmural lesions when used from the epicardium on the beating, filled heart? Fortunately, this is a purely technical question; with the right animal (and perhaps human) models it can be definitively answered. The second question, however, is much more vexing: Are transmural lesions necessary to cure atrial fibrillation? We certainly have an extensive and detailed database gathered over the last 15 years concerning the Maze operation, a procedure that ensured transmurality by virtue of its cut-and-sew lesions; we know the results with that approach. As the field of atrial fibrillation surgery moves to less-destructive and less-invasive methods in a drive to treat more patients, it may no longer be possible to use this experience as a guide.

Let us first consider the question of transmural lesion creation. There is a bewildering array of ablative energy sources available to the surgeon in 2006: Dry unipolar radiofrequency (RF), dry bipolar RF, irrigated unipolar RF, irrigated bipolar RF, microwave, laser, ultrasound, and cryothermy. There are even investigations into the use of $\beta$ radiation. All of these devices have been used in the open-chest setting and many are even available in a percutaneous delivery vehicle.

When applied from the endocardium on an arrested, cooled heart, nearly all of the energy sources appear able to create deep, transmural, and fairly well-controlled lesions. However, when applied from the epicardium while the heart is beating and filled with blood, the situation is quite different. Unipolar RF does not appear to create transmural lesions too well: Only $22 \%$ of lesions were transmural acutely in a human study, ${ }^{2}$ and only $33 \%$ were transmural acutely in a sheep model. ${ }^{2}$ Bipolar RF was more effective, achieving transmurality between $92 \%$ and $100 \%$ of the time in a variety of experimental situations, acutely or chronically, on or off cardiopulmonary bypass. ${ }^{3-7}$

It is likely that the single most significant difference here is whether the device can stop blood flow near the ablating element, eliminating the thermal sink effect and greatly increasing the depth of lesion penetration. This hypothesis is supported by investigations on the effects of cryothermy, in which ablation from the epicardium on beating hearts of dogs demonstrated that $93 \%$ of clamped were transmural, yet only $84 \%$ of linear, unclamped lesions completely crossed the atrial wall. ${ }^{8}$ Unfortunately, this increase in efficacy comes at the expense of much more limited device flexibility.

Microwave radiation, a unipolar ablation method, has shown inconsistent results with transmurality achieved from the epicardium in $48 \%$ to $100 \%$ of applications. ${ }^{9-11}$ In our laboratory we too have been studying microwave radiation and have found that $89 \%$ of acute epicardial beating-heart lesions are transmural; how many more "become" transmural after 3 months of recovery is still under investigation and should help determine whether scar formation and healing are important factors in producing transmural lesions over the long term. 
In 2006, therefore, the surgeon is faced with this dilemma: Bipolar clamp devices are more effective at creating transmural lesions yet are larger and less "minimally invasive," whereas unipolar devices are more flexible, generally of lower profile, and "easier" to use with minimal access techniques yet do not so predictably create transmural lesions (there is too much reliance on energy dosimetry). In the best of all worlds the surgeon would use a device that is small, flexible, adaptable to any lesion pattern, and yet gives some kind of real-time feedback ensuring that a transmural lesion has been made.

Yet is this really necessary? Is a transmural lesion required to effectively "cure" atrial fibrillation? Indeed, why do many clinical studies document an $80 \%$ or higher cure rate when the preclinical data do not show nearly so high a transmurality rate? This is the second question posed earlier: Is transmurality necessary? There is evidence accumulating from the catheter-based approach that it is likely not required and in fact is often not achieved during ablation when electrical isolation is used as the treatment end point. ${ }^{12-14}$ So, if we are not aiming for transmurality, then what is our goal?

Perhaps tissue temperature is a better measure of the adequacy and predictability of lesion formation. In a study of isolated guinea pig hearts, perfusion with fluid temperature greater than $55^{\circ} \mathrm{C}$ resulted in irreversible cessation of electrical conduction, whereas perfusion with fluid temperature of $45^{\circ} \mathrm{C}$ to $55^{\circ} \mathrm{C}$ only temporarily arrested conduction. ${ }^{15}$ In our laboratory we have found that epicardial microwave energy increases right ventricular endocardial free wall tissue temperature to more than $55^{\circ} \mathrm{C}$ after 80 seconds at 65 watts. We have not studied the atrium, where the heat sink effect of flowing blood may be more pronounced. Furthermore, we fully appreciate the technical challenge associated with performing such measurements in clinical application.

So what are the answers to the questions facing us in 2006? As we strive to perfect a procedure that can effectively treat atrial fibrillation while being minimally invasive, we do not yet have the perfect tool. Much work still needs to be done to develop a device or devices that can reliably create transmural lesions in atrial muscle while the heart is full and beating. We also must determine what end points should be measured during ablation so the operating surgeon can be sure that he or she is creating an adequate injury. Whether that injury actually needs to be transmural or to a certain temperature or perhaps to some other mea- surement also remains to be determined. Melby and colleagues ${ }^{1}$ are to be congratulated for taking the first brave step into this wilderness. Their contribution is a valuable one and sets the mark for future studies in this exciting, developing field.

\section{References}

1. Melby SJ, Zierer A, Kaiser SP, Schuessler RB, Damiano RJ, Jr. Epicardial microwave ablation on the beating heart for atrial fibrillation: the dependency of lesion depth on cardiac output. J Thorac Cardiovasc Surg. 2006;132:355-60.

2. Melo J, Adragao P, Neves J, Ferreira M, Timoteo A, Santiago T, et al. Endocardial and epicardial radiofrequency ablation in the treatment of atrial fibrillation with a new intra-operative device. Eur J Cardiothorac Surg. 2000;18:182-6.

3. Bugge E, Nicholson IA, Thomas SP. Comparison of bipolar and unipolar radiofrequency ablation in an in vivo experimental model. Eur J Cardiothorac Surg. 2005;28:76-80; discussion 80-2.

4. Hamner CE, Potter DDJ, Cho KR, Lutterman A, Francischelli D, Sundt TMr, et al. Irrigated radiofrequency ablation with transmurality feedback reliably produces Cox maze lesions in vivo. Ann Thorac Surg. 2005;80:2263-70.

5. Hamner CE, Lutterman A, Potter DD, Sundt TMr, Schaff HV, Francischelli D. Irrigated bipolar radiofrequency ablation with transmurality feedback for the surgical Cox-Maze procedure. Heart Surg Forum. 2003;6:418-23.

6. Prasad SM, Maniar HS, Moustakidis P, Schuessler RB, Damiano RJJ. Epicardial ablation on the beating heart: progress towards an off-pump maze procedure. Heart Surg Forum. 2002;5:100-4.

7. Prasad SM, Maniar HS, Schuessler RB, Damiano RJJ. Chronic transmural atrial ablation by using bipolar radiofrequency energy on the beating heart. J Thorac Cardiovasc Surg. 2002;124:708-13.

8. Milla F, Skubas N, Briggs WM, Girardi LN, Lee LY, Ko W, et al. Epicardial beating heart cryoablation using a novel argon-based cryoclamp and linear probe. J Thorac Cardiovasc Surg. 2006;131: 403-11.

9. Smith JM, Hassan M, Ignacio R. Robot-assisted isolation of the pulmonary veins with microwave energy. J Card Surg. 2006;21:83-8.

10. Accord RE, van Suylen RJ, van Brakel TJ, Maessen JG. Post-mortem histologic evaluation of microwave lesions after epicardial pulmonary vein isolation for atrial fibrillation. Ann Thorac Surg. 2005;80:881-7.

11. van Brakel TJ, Bolotin G, Salleng KJ, Nifong LW, Allessie MA, Chitwood WRJ, et al. Evaluation of epicardial microwave ablation lesions: histology versus electrophysiology. Ann Thorac Surg. 2004; 78:1397-402; discussion 1397-402.

12. Schwartzman D, Michele JJ, Trankiem CT, Ren JF. Electrogramguided radiofrequency catheter ablation of atrial tissue comparison with thermometry-guide ablation: comparison with thermometry-guide ablation. J Interv Card Electrophysiol. 2001;5:253-66.

13. Avitall B, Urbonas A, Urboniene D, Malhotra V, Millard SC, Bharati $\mathrm{S}$. The ablation of atrial fibrillation with the loop catheter design: what we have learned from the animal model. Pacing Clin Electrophysiol. 2001;24:1138-49.

14. Lemola K, Hall B, Cheung P, Good E, Han J, Tamirisa K, et al. Mechanisms of recurrent atrial fibrillation after pulmonary vein isolation by segmental ostial ablation. Heart Rhythm. 2004;1:197-202.

15. Nath S, Lynch CR, Whayne JG, Haines DE. Cellular electrophysiological effects of hyperthermia on isolated guinea pig papillary muscle. Implications for catheter ablation. Circulation. 1993;88:1826-31. 